\title{
Yeni bir Sıvı Membran Sistemi (ÇDSM) ile Ağır Metal İyonlarının Ekstraksiyonu
}

\author{
Kadriye ESEN ERDEN ${ }^{1 *}$, Ramazan DONAT $^{2}$
}

Geliş / Received: $18 / 03 / 2020$

Revize / Revised: 02/06/2020

Kabul / Accepted: 03/06/2020

\section{$\overline{\mathbf{O Z Z}}$}

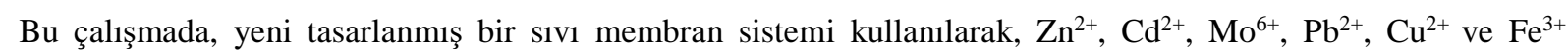
iyonlarının taşınması ve taşınımı etkileyen faktörler incelenmiştir. Çalışmada, literatürde mevcut diğer sıvı membran tekniklerinden farklı yeni bir yöntem uygulanmıştır. Bu yöntem, donör ve akseptör fazdan ligand taşıyıcısı içeren organik fazın damlacıklar halinde geçirilmesiyle küçük bir farklılık göstermekle beraber, hacimli sıv1 membran sistemi ile benzerdir. Sistem "Çok Damlalı Sıv1 Membran Sistemi” (ÇDSM) olarak adlandırılmıştır. Bu tekniğin avantajları arasında basit yapı, hareketli parça azlığı, hafif ve taşınabilir olması, esnek çalışma, yüksek membran kapasitesi ve yüksek ayırma faktörü sayılabilir. Bu yeni yöntem ile çalışma süresi, kontaminasyon riski, kullanılan reaktif miktarları ve üretilen atık miktarlarının azaltılması amaçlanmaktadır. Sistem $\mathrm{Zn}^{2+}, \mathrm{Cd}^{2+}, \mathrm{Mo}^{6+}, \mathrm{Pb}^{2+}, \mathrm{Cu}^{2+}$ ve $\mathrm{Fe}^{3+}$ iyonlarının sulu çözeltilerden taşınması için uygulanmış ve başarılı sonuçlar elde edilmiştir. Her bir metal iyonu için uygun donör, taşıyıcı ve akseptör çözeltiler ile optimum taşınım koşulları (donör ve akseptör faz derişimleri ile pH'ları, organik faz derişimi, sıcaklık, akış hızı) belirlenmiştir. Ard arda tersinmez I. mertebe reaksiyon varsayımıyla $\boldsymbol{k}_{\mathbf{1}}, \boldsymbol{k}_{\mathbf{2}}, \boldsymbol{C}_{\boldsymbol{B}}^{\boldsymbol{m a k}}, \boldsymbol{t}_{\boldsymbol{B}}^{\text {mak }}$ kinetik parametreleri, fazlar arası kütle aktarımı kanunları ile $\boldsymbol{J}_{\boldsymbol{d}}^{\boldsymbol{m a k}}, \boldsymbol{J}_{\boldsymbol{a}}^{\boldsymbol{m a k}}$ değerleri ve aktivasyon enerjisi $\left(\boldsymbol{E}_{\boldsymbol{a}}\right)$ değerleri hesaplanmıştır. Sonuçlar, mevcut deneysel çalışmalarda kullanılan ÇDSM sisteminin, ağır metal endüstrilerinin neden olduğu ağır metal iyonlarını gidermek için mükemmel bir alternatif ve ekonomik süreç olabileceğini düşündürmektedir.

\section{Anahtar Kelimeler- Stvı membran,Ekstraksiyon, A ğır metaller, Taşınım, ÇDSM}

\footnotetext{
1*Sorumlu yazar iletişim: kadriye.erden@kocaeli.edu.tr (https://orcid.org/0000-0002-6108-9489) Elektrik ve Enerji Bölümü, Kocaeli Üniversitesi Uzunçiftlik Nuh Çimento Meslek Yüksekokulu, Kocaeli, Türkiye 2İletişim: rdonat@pau.edu.tr ( https:// orcid.org/0000-0002-5701-5030)

Kimya Bölümü, Pamukkale Üniversitesi, Fen Edebiyat Fakültesi, Denizli, Türkiye
} 


\title{
Extraction of Heavy Metal Ions through a Novel Liquid Membrane System (MDLM)
}

\begin{abstract}
In this study, the transport and factors affecting the transport of $\mathrm{Zn}^{2+}, \mathrm{Cd}^{2+}, \mathrm{Mo}^{6+}, \mathrm{Pb}^{2+}, \mathrm{Cu}^{2+}$ and $\mathrm{Fe}^{3+}$ ions using a newly designed liquid membrane system were investigated. In the study, a new method, different from other liquid membrane techniques available in the literature, has been applied. This method is similar to the bulk liquid membrane system, as it differs slightly by passing the organic phase containing the ligand carrier from the donor and acceptor phase into droplets. It is called as "Multi Dropped Liquid Membrane System" (MDLM). The advantages of this technique include simple structure, lack of moving parts, light and portable, flexible operation, high membrane capacity and high separation factor. With this new method, it is aimed to reduce the working time, the risk of contamination, the amount of reagents used and the amount of waste produced. The system has been applied for transport of $\mathrm{Zn}^{2+}, \mathrm{Cd}^{2+}, \mathrm{Mo}^{6+}, \mathrm{Pb}^{2+}, \mathrm{Cu}^{2+}$ and $\mathrm{Fe}^{3+}$ ions from aqueous solutions and successful results have been obtained. Optimum transport conditions (donor and acceptor phase concentrations and $\mathrm{pH}$, organic phase concentration, temperature, flow rate) were determined with suitable donor, carrier and acceptor solutions for each metal ion. The kinetic parameters $\boldsymbol{k}_{\mathbf{1}}, \boldsymbol{k}_{\mathbf{2}}, \boldsymbol{C}_{\boldsymbol{b}}^{\max }, \boldsymbol{t}_{\boldsymbol{B}}^{\max }$ and activation energy $\left(\boldsymbol{E}_{\boldsymbol{a}}\right)$ were calculated for the interface reactions assuming two consecutive, irreversible first-order reactions, $\boldsymbol{J}_{\boldsymbol{d}}^{\max }, \boldsymbol{J}_{\boldsymbol{a}}^{\max }$ were calculated with interphase mass transfer laws. The results suggest that the MDLM system that used in the current experimental studies can be a great alternative and economical process in order to remove the heavy metal ions caused by heavy metal industries.
\end{abstract}




\section{GİRIȘ}

Ağır metallerin birçok olumsuz sağlık etkisi uzun süredir bilinmesine rağmen, insanlar tarafından binlerce yıldır kullanılmaktadır. Ağır metallerden insan sağlı̆̆ına yönelik ana tehditleri kurşun, kadmiyum, cıva ve arsenik maruziyetiyle ilişkilidir. Bu ağır metaller kapsamlı bir şekilde yıllardır incelenmekte ve insan sağlı̆ğ üzerindeki etkileri Dünya Sağlık Örgütü gibi uluslararası kuruluşlar tarafından düzenli olarak gözden geçirilmektedir [1].

$\mathrm{Pb}^{2+}, \mathrm{Cd}^{2+}, \mathrm{Cr}^{6+}, \mathrm{Hg}^{2+}, \mathrm{Cu}^{2+}$ vb. gibi ağır metal iyonları, metal kaplama, seramik, kâğıt hamuru, kurşun eriticiler, elektrokaplama, madencilik ve pil imalat endüstrilerinden çevreye deşarj edilmektedir [2]. Bu ağır metal iyonlarının neden olduğu su kirliliği, insanlar için gıda zinciri yoluyla insan vücuduna nüfuz edebildikleri için ve böylece kansere, merkezi sinir sistemi hasarına, akciğer hasarına, beynin hasar görmesine ve nihayetinde ölüme yol açabilir [3]. Bu nedenle, zehirli ağır metal kirleticilerinin sulu atık akışlarından uzaklaştırılması halen araştırılmakta olan önemli çevresel sorunlardan biridir.

Yıllardır ağır metal iyonlarını gidermek için; kimyasal çökeltme, iyon değişimi, adsorpsiyon, flotasyon, ekstraksiyon, elektrokimyasal metotlar ve membran ayırma gibi birçok teknoloji araştırılmıştır ve kullanılmaktadır. Bununla birlikte bu ayırma yöntemlerinden bazıları verim düşüklüğü, yüksek maliyet, hassas çalışma koşulları ve ikincil çamur üretimi gibi bazı dezavantajlara sahip olduklarından çok popüler değildir [4]. Çözücü ekstraksiyonu işlemi, saflaştırma, metal iyonlarının sulu çözeltilerden geri kazanılması ve ayrılmasında yaygın olarak kullanılan ayırma tekniklerinden biridir. Çözücü ekstraksiyonu diğer ayırma teknikleriyle kıyaslandığında; uzun zaman gerektirmesi ve büyük miktarda organik çözücü kullanması dezavantajını taşımaktadır. Çok miktarda çözücünün zararsız hale getirilmesi yüksek maliyet dezavantajı yanında, aynı zamanda çevresel de bir problemdir [5]. Bu nedenle günümüzde popüler bir bilim haline gelen membran teknolojisinin alternatif metodlarından biri olan sıvı membran tekniği ilgi görmektedir. Sıvı membran prosesi, tek bir adımda ekstraksiyon ve ekstrakte edilen metal iyonlarının sökülmesi proseslerinden meydana geldiği için, çözücü ihtiyacını azaltmakta ve daha ekonomik olarak gerçekleşmektedir. Bu sebepten sıvı membran prosesleri dünyadaki birçok araştırmacının ilgisini çekmekte ve çeşitli metal iyonlarının ayrılması için oldukça fazla çalışma yapılmaktadır.

Sıvı membran teknolojisi, sulu donör çözeltisinden metal iyonunun taşıyıcı molekülleri (membran) içeren organik faza tek aşamalı ekstraksiyonu ve bu metal iyonunun membran fazdan sulu akseptör faza tekrar ekstraksiyonu olmak üzere iki aşamadan oluşur. Sıvı membran proseslerin potansiyel avantajları arasında; yüksek ayırma faktörleri katı membranlara göre daha yüksek kütle alanları, çok yüksek seçicilik, düşük konsantrasyondan yüksek konsantrasyona ayırma ve zenginleştirme, pahalı ekstrakte edicilerin kullanılabilmesi, yüksek besleme/çözücü hacim oranları, askıda katı madde içeren çözeltilerin işlenebilmesi, ölçeklendirme kolaylığı, düşük yatırım ve işletme maliyeti sayılabilir [6]. Sıvı membranlar çeşitlerine göre yüzey aktif, organik çözücü ve taşıyıcı (ekstrakte edici) maddelerin her üçünü içerebildikleri gibi bunların farklı kombinasyonlarına da sahip olabilmektedirler.

Bu çalışmada, literatürde mevcut olan sıvı membran tekniklerinden farklı, yeni bir sıvı membran tekniği ile, $\mathrm{Zn}^{2+}, \mathrm{Cd}^{2+}, \mathrm{Mo}^{6+}, \mathrm{Pb}^{2+}, \mathrm{Cu}^{2+}$ ve $\mathrm{Fe}^{3+}$ iyonlarının taşınması, geri alım verimleri, hesaplanan kinetik parametreleri yanında diğer sıvı membranlarla yapılan çalışmalarda elde edilen sonuçlar karşılaştırılmıştır.

\section{MALZEME VE YÖNTEM}

Deneylerde kullanılan tüm kimyasallar analitik safıktadır. Bu çalışmada kullanılan sıvı membran sisteminin bir fotoğrafı ve şeması Şekil 1'de gösterilmektedir. Sistem tamamıyla Pamukkale Üniversitesi Fen Edebiyat Fakültesi Kimya Bölümü öğretim üyeleri Prof. Dr. Halil Çetişli ve Dr. Öğr. Üyesi Ramazan Donat tarafından tasarlanmıştır. Sistem genel hatlarıyla iki reaktörden oluşur. İlk reaktörün alt kısmında metal iyonları ve üstte uygun çözücü organik faz içinde organik ligandların yer alırken diğer reaktörde ise alt kısımda sıyırma fazı ve üstte yine organik faz içinde organik ligandlar yer almaktadır. Programlanan sabit sıcaklıkta çalışabilmek için sirkülasyonlu kreostat cihazından alınan akışkan tüm reaktör sisteminin dış ceketinden dolaştırılmaktadır. Sabit taşınım hızı sağlamak için de sistem peristaltik pompaya bağlanmıştır. Mekanik karıştırıcının bertaraf edilmesi ve damlacıkların daha homojen dağılmasını sağlamak amacıyla reaktörlerin tabanında poröz cam 
kullanılması uygun görülerek sistem geliştirilmiştir. Organik faz, peristaltik pompa yardımı ile her iki reaktörün altındaki gözenekler yoluyla çoklu damlacıklar halinde tüm sistemi dolaşmaktadır. Organik faz; donör ve akseptör fazlardan kabarcıklar halinde geçer ve ilgili fazlarda yukarıya doğru hareket ederek taşıyıcı reaktifmetal iyonu teması sağlanmıştır.

Örnekler, reaktörlerdeki musluklar yardımıyla ilk (donör faz) ve ikinci reaktörlerden (akseptör faz) beş dakika arayla alınmış ve her bir metal iyonu tayini için uygun yöntemler kullanılarak UV-Vis spektrofotometre ile analiz edilmiştir. İzah edildiği gibi gerçekleştirilen ekstraksiyon sistemi Çok Damlacıklı Sıvı Membran (ÇDSM) Sistemi olarak tanımlanmıştır.

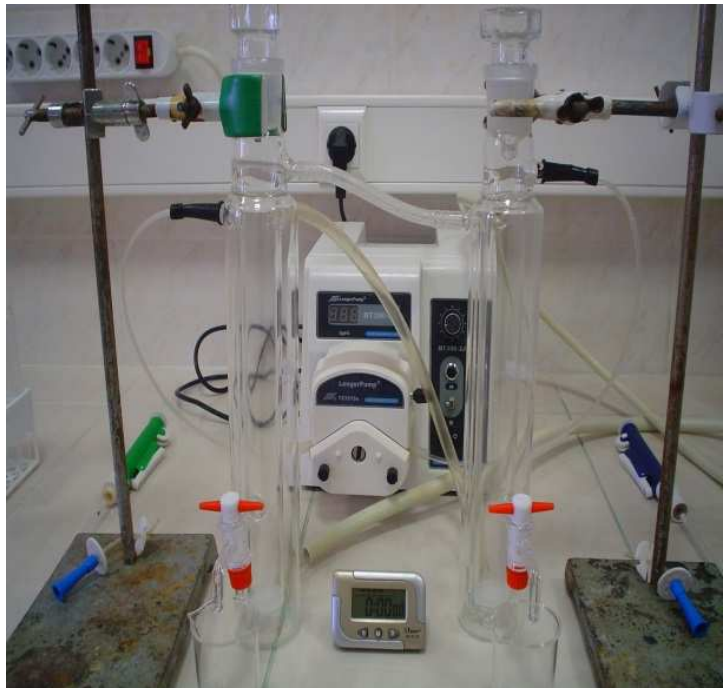

(a)

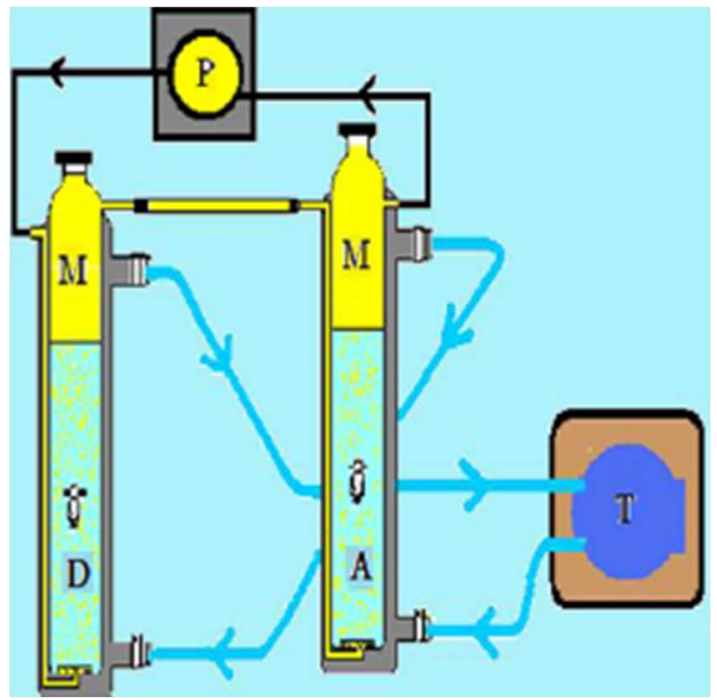

(b)

Şekil 1. Çok Damlacıklı Sıvı Membran Ekstraksiyon Sistemi’nin a) Fotoğrafı b) Şeması (M: Organik faz, D: Donör faz, A: Akseptör faz, P: Peristaltik pompa, T: Termostat)

Deneysel çalışmalar ÇDSM sisteminde gerçekleştirilmiş, taşıyıcı ligand seçimi için literatürde sıkça karşılaşılan taşıyıcı ligand türleri öncelikli olarak kullanılmıştır. ÇDSM sisteminde $\mathrm{Zn}^{2+}, \mathrm{Cd}^{2+}, \mathrm{Mo}^{6+}, \mathrm{Pb}^{2+}, \mathrm{Cu}^{2+}$, $\mathrm{Fe}^{3+}$ iyonlarının ekstraksiyonu için uygun donör, akseptör fazlar ve her bir metal iyonu taşınımı için uygun organik ligand ve çözücüsünden oluşan ekstraktör fazlar belirlenmiştir. Her bir metal iyonu için optimum taşınım koşulları; donör ve akseptör faz derişimleri ile pH'ları, taşıyıcı faz derişimi, sıcaklık ve membran akış hızının etkileri araştırılmıştır. ÇDSM sistemi ile çalışmalara başlandıktan sonra belirli sürelerle hem donör fazdan hem de akseptör fazdan örnekler alınarak fazlardaki metal iyonu derişimleri UV-Vis spektrofotometresi kullanılarak kolorimetrik olarak tayin edilmiştir. $\mathrm{Mo}^{6+}, \mathrm{Pb}^{2+}, \mathrm{Cu}^{2+}, \mathrm{Fe}^{3+}$ iyonlarına ait yarışmalı ekstraksiyon deneylerinde fazlardaki metal iyonu derişimleri ICP-OES kullanılarak belirlenmiştir.

\section{A. Kinetik Hesaplamalar}

Ekstraksiyon kinetiği grafiklerine göre fazlardaki reaktif derişimlerinin zamanla değişimi ard arda gerçekleşen 1. mertebe tepkime modeline benzemektedir. $\mathrm{Bu}$ model mevcut deneysel çalışmalara uyarlandığında,

$$
A \stackrel{k_{i}}{\rightarrow} \rightarrow B \stackrel{k_{i}}{\rightarrow} \rightarrow C
$$
sabitleridir.

A donör, B organik ve $\mathrm{C}$ de akseptör fazdaki reaktif derişimini simgelemektedir. $k_{l}$ ve $k_{2}$ reaksiyon hız 
Ekstraksiyon ve sıyırma işlemleri, ardışık birinci dereceden reaksiyon kinetiklerine uyduğundan reaksiyon hızı sabitleri, farklı sıcaklıklarda farklı değerler almaktadır. Bu nedenle, donör fazda belirlenen reaktif derişimleri kullanılarak zamana karşı $\ln \left(C_{o} / C_{e}\right)$ değişim grafikleri oluşturulmuş ve kinetik veriler elde edilmiştir. $C_{o}$ metalin başlangıç konsantrasyonunu $C_{e}$ ise herhangi bir t anındaki konsantrasyonunu sembolize etmektedir. $\mathrm{Bu}$ grafiğin eğimi $k_{l}$ reaksiyon hız sabitini vermektedir. Arabirim reaksiyonları için kinetik parametreler $k_{1}, k_{2}$, $C_{B}^{\text {mak }}, t_{B}^{\text {mak }}, J_{d}^{\text {mak }}, J_{a}^{\text {mak }}$ ve aktivasyon enerjisi $\left(E_{a}\right)$ iki ardışık, tersinmez birinci mertebeden reaksiyon varsayımıyla hesaplanmıştır. $t_{\text {max }}$ B'nin maksimum derişime ulaştığı süre ve $C_{B}^{\text {mak }}$ ' da B'nin ulaştığı maksimum derişimi sembolize etmektedir. $k_{2}, t_{B}^{\text {mak }}$ ve $C_{B}^{\text {mak }}$ değerleri 1,2 ve 3 formülleri yardımı ile hesaplanmıştır. [7,8].

$$
\begin{aligned}
& t_{B}^{\text {mak }}=\frac{\ln \left(k_{1} / k_{1}\right)}{k_{1}-k_{2}} \\
& C_{B}^{\text {mak }}=C_{\mathrm{o}}\left(\frac{k_{2}}{k_{1}}\right)^{\frac{k_{2}}{k_{1}-k_{2}}} \\
& k_{2}=\frac{-\ln \left(\frac{C_{B}^{\text {mak }}}{C_{a}^{0}}\right)}{t_{B}^{\text {mak }}}
\end{aligned}
$$

Ayrıca her bir deney için, $k_{l}$ ve $k_{2}$ reaksiyon hız sabitlerine bağlı olarak sırasıyla, membran giriş $\left(J_{d}^{\text {mak }}\right)$ ve membrandan çıkış $\left(J_{a}^{\text {mak }}\right)$ hızları 4,5 ve 6 formülleri yardımıyla hesaplanmıştır [7].

$$
\begin{aligned}
& J_{d}^{\text {mak }}=\frac{d R_{d}}{d_{t}} \\
& J_{d}^{\text {mak }}=\left.\frac{d R_{d}}{d_{t}}\right|_{m a k}=-k_{1}\left(\frac{k_{1}}{k_{2}}\right)^{-k_{1} /\left(k_{1}-k_{2}\right)} \\
& J_{a}^{\text {mak }}=\left.\frac{d R_{a}}{d_{t}}\right|_{m a k}=k_{2}\left(\frac{k_{1}}{k_{2}}\right)^{-k_{2} /\left(k_{1}-k_{2}\right)}
\end{aligned}
$$

Aktivasyon enerjisi $\left(E_{a}\right)$ değerleri, maksimum membran çıkış hızlarına karşılık 1/T değerlerinin farklı sıcaklık aralıkları için grafiğe geçirilmesiyle elde edilen $k_{l}$ ve $k_{2}$ değerleri kullanılarak Arrhenius denklemi (7) yardımıyla elde edilmiştir [9].

$$
\ln (J)=\ln (A)-\frac{E_{\mathrm{a}}}{R}\left(\frac{1}{T}\right)
$$

\section{BULGULAR VE TARTIŞMA}

ÇDSM sisteminde $\mathrm{Zn}^{2+}, \mathrm{Cd}^{2+}, \mathrm{Mo}^{6+}, \mathrm{Pb}^{2+}, \mathrm{Cu}^{2+}, \mathrm{Fe}^{3+}$ iyonlarının ekstraksiyonu gerçekleştirilmişstir. Bunun için ilk olarak uygun donör, akseptör fazlar ve her bir metal iyonu taşınımı için uygun organik ligand ve çözücüsünden oluşan ekstraktör fazlar belirlenmiştir. Bu fazların derişimleri, pH'ları, deney sıcaklığı ve membran akış hızının etkileri her bir metal iyonu için ayrı ayrı araştırılmıştır.

Çinko metali ile yapılan çalışmalarda; belirlenen optimum donör faz derişimi 100 mg/L, pH'1 5, en yüksek sıyırmanın gerçekleştirildiği akseptör faz derişimi de $0.25 \mathrm{~mol} / \mathrm{L} \mathrm{HCl}$ çözeltisi olarak belirlenmiştir. Membran faz olarak kerozen içerisinde çözülmüş $8 \times 10^{-3} \mathrm{~mol} / \mathrm{L}$ di-(2-etil hegzil) fosforik asit (D2EHPA) ligandı en verimli (\%99.20) sonucu göstermiş olup optimum sıcaklık 308.15K ve membran akış hızı 62mL/dak olarak deneyler gerçekleştirilmiştir. D2EHPA taşıyıcı için $\mathrm{Zn}^{2+}$ iyonunun taşınımı için aktivasyon enerjisi $\left(E_{\mathrm{a}}\right)$ değeri $5.30 \mathrm{kcal} / \mathrm{mol}$ olarak hesaplanmış olup; bulunan aktivasyon enerjisi değeri $10 \mathrm{kcal} / \mathrm{mol}$ 'den küçük olmasından dolayı difüzyon kontrollü olduğunu göstermektedir. Deney sonuçlarına göre ÇDSM sisteminde D2EHPA taşıyıcısı kullanılarak $\mathrm{Zn}^{2+}$ iyonlarının \%99 verimle taşınması mümkün olduğu söylenebilir [10]. Çinko metali ile yapılan çalışmalarda birçok deneme sonucunda belirlenen optimum parametrelerde gerçekleştirilen deneye ait fazlardaki çinko derişiminin zamanla değişim grafiği ve ekstraksiyon kinetiği grafiği Şekil 2'de verilmiştir. 


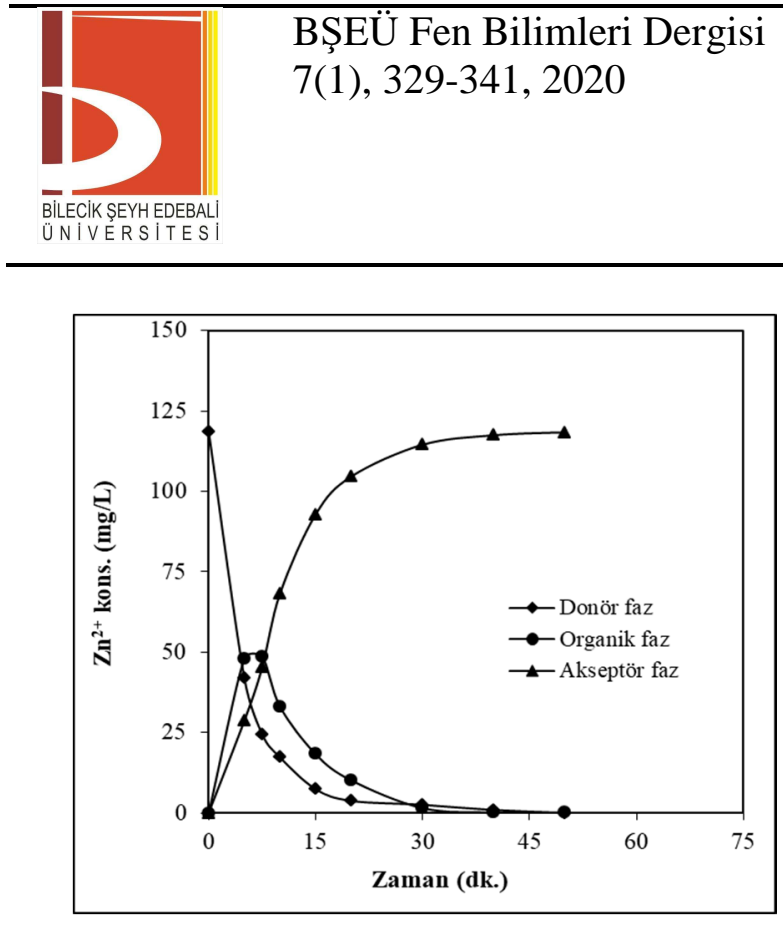

(a)
BSEU Journal of Science

DOI: 10.35193/bseufbd.705604

Şekil 2. (a) Donör, akseptör ve organik fazlardaki Çinko iyonları derişiminin zamanla değişim grafiği, (b) Çinko için ekstraksiyon kinetiği grafiği

Çok damlacıklı sıvı membran sisteminde $\mathrm{Cd}^{2+}$ iyonlarının ekstraksiyonu; kerozen içinde çözünmüş taşıyıcı tri-n-oktil amin (TNOA) ve akseptör faz olarak amonyum asetat içeren çözelti ile incelenmiştir. Kadmiyum metali ile yapılan çalışmalarda en uygun organik faz derişimi $7 \times 10^{-3} \mathrm{~mol} / \mathrm{L}$ 'lik tri-n-oktil amin ve akseptör faz derişimi de $0.5 \mathrm{~mol} / \mathrm{L}$ olarak belirlenmiştir. $288.15 \mathrm{~K}$ 'de yürütülen deney sonuçlarına göre $\% 98$ verim ile $\mathrm{Cd}^{2+}$ iyonları transferi gerçekleştirilmiştir [11]. Fazlardaki $\mathrm{Cd}^{2+}$ iyonlarının zamanla değişim grafiği ve ekstraksiyon kinetiği grafikleri Şekil 3 'te verilmiştir.

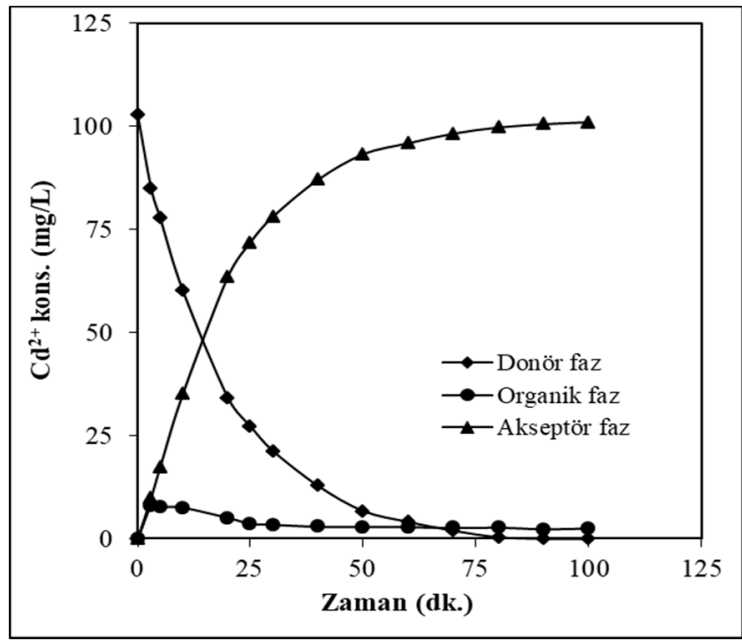

(a)

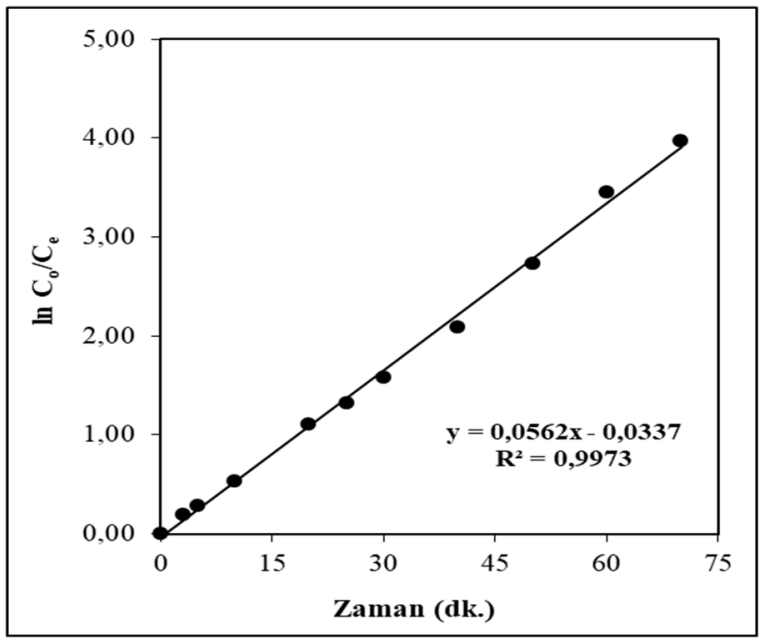

(b)

Şekil 3. (a) Donör, akseptör ve organik fazlardaki Kadmiyum iyonları derişiminin zamanla değişim grafiği, (b) Kadmiyum için ekstraksiyon kinetiği grafiği

Donör, akseptör ve organik fazdaki $\mathrm{Cd}^{2+}$ iyonlarının zamanla azalan konsantrasyon eğrileri elde edilen deneysel verilerle iyi bir uyum göstermiş olup $\mathrm{Cd}^{2+}$ iyonlarının ekstraksiyon mekanizmasına ait aktivasyon 
enerjisi, $17.07 \mathrm{kcal} / \mathrm{mol}$ olarak hesaplanmıştır. Bu değer ÇDSM sistemi ile $\mathrm{Cd}^{2+}$ iyonlarının ekstraksiyonunun kimyasal kontrollü olduğunu göstermiştir. Deneysel sonuçlara göre çok damlacıklı sıvı membran sistemine dayanan bir ekstraksiyon ile sulu çözeltiden $\mathrm{Cd}^{2+}$ iyonlarının uzaklaştırılmasının $\% 98$ verimle mümkün olduğunu göstermektedir [11].

Molibden metali ile yapılan çalışmalarda taşıyıcı faz olarak kerosen içerisinde çözünmüş $5 \times 10^{-}$ ${ }^{3}$ mol/L'lik TNOA en yüksek taşınımı sağlamış olup akseptör fazda $1.00 \mathrm{~mol} / \mathrm{L} \mathrm{Na}_{2} \mathrm{CO}_{3}$ çözeltisi kullanılmıştır. Akseptör fazda kullanılan sodyum karbonat derişimi arttıkça, akseptör faza geçen $\mathrm{Mo}^{6+}$ iyonlarının derişimi de artmış olup, yüksek sodyum karbonat derişimlerinde, ekstraksiyon çok hızlı gerçekleşmiştir. Ekstraksiyon için en uygun sodyum karbonat derişimi $1.00 \mathrm{~mol} / \mathrm{L}$ olarak belirlenmiştir $298.15 \mathrm{~K}$ sicaklıkta 50mL/dak membran akış hızında belirlenen derişim ve pH'lardaki fazlar ile çalışıldığında \%98.6'lık bir transfer yüzdesi ile Molibden iyonları taşınımı gerçekleştirilmiştir. Fazlardaki $\mathrm{Mo}^{6+}$ iyonunun zamanla değişim grafiği ve ekstraksiyon kinetiği grafikleri Şekil 4'te verilmiştir. TNOA taşıyıcı için $\mathrm{Mo}^{6+}$ iyonunun taşınımı için $6.09 \mathrm{kcal} / \mathrm{mol}$ olarak hesaplanan aktivasyon enerjisi değeri, $10 \mathrm{kcal} / \mathrm{mol}$ 'den küçük olmasından dolayı olayın difüzyon kontrollü olduğunu göstermektedir [12].

Optimum koşullarda donör fazda $\mathrm{Mo}^{6+}$ iyonları yanında $\mathrm{K}^{+}, \mathrm{Ca}^{2+}$ ve $\mathrm{Ba}^{2+}$ iyonlarının bulunması halinde gerçekleştirilen yarışmalı esktraksiyon deneylerinde; $\mathrm{Mo}^{6+}$ iyonlarının donör fazdan akseptör faza transportunda ekstraksiyon verimleri artmış, ekstraksiyon süresi uzamış, hız sabiti düşmüş ve akış hızı azalmıştır. Gerçekleştirilen deney sonucunda alev fotometresi ile yapılan ölçümlere göre akseptör fazda potasyum iyonlarına rastlanmamış, kalsiyum ve baryumun ise sırasıyla \%8.32 ve \%15.00 oranında akseptör faza geçtiği belirlenmiştir. Yine optimum koşullarda donör fazda $\mathrm{Mo}^{6+}$ çözeltisi yanında $\mathrm{Cu}^{2+}, \mathrm{Fe}^{3+}, \mathrm{Pb}^{2+}, \mathrm{Zn}^{2+}$ ve $\mathrm{Co}^{2+}$ iyonlarının bulunması halinde gerçekleştirilen yarışmalı ekstraksiyon deneylerinde, $\mathrm{Mo}^{6+}$ iyonlarının ekstraksiyon verimi artmış, ekstraksiyon süresi uzamış, hız sabiti değerlerinde değişim gözlenirken, akış hızı azalmıştır. Deneyler sonunda ICP-OES ile yapılan ölçümler sonucunda akseptör fazda $\mathrm{Cu}^{2+}, \mathrm{Fe}^{3+}, \mathrm{Pb}^{2+}, \mathrm{Zn}^{2+}$ ve $\mathrm{Co}^{2+}$ iyonlarından hiçbirine rastlanmamış olup bu çalışma $\mathrm{Mo}^{6+}$ iyonlarınının ekstraksiyonu için yüksek seçicilik gösteren bir çalışma olmuştur [13].

Elde edilen sonuçlar, $\mathrm{Mo}^{6+}$ iyonlarının ekstraksiyonunun, ÇDSM sistemi kullanılarak yüksek verimle gerçekleştirilebileceğini göstermektedir.

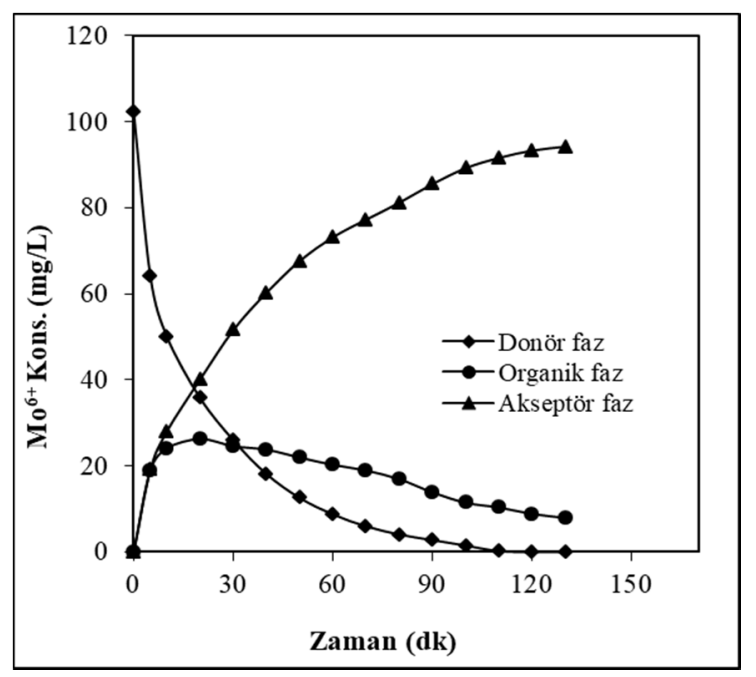

(a)

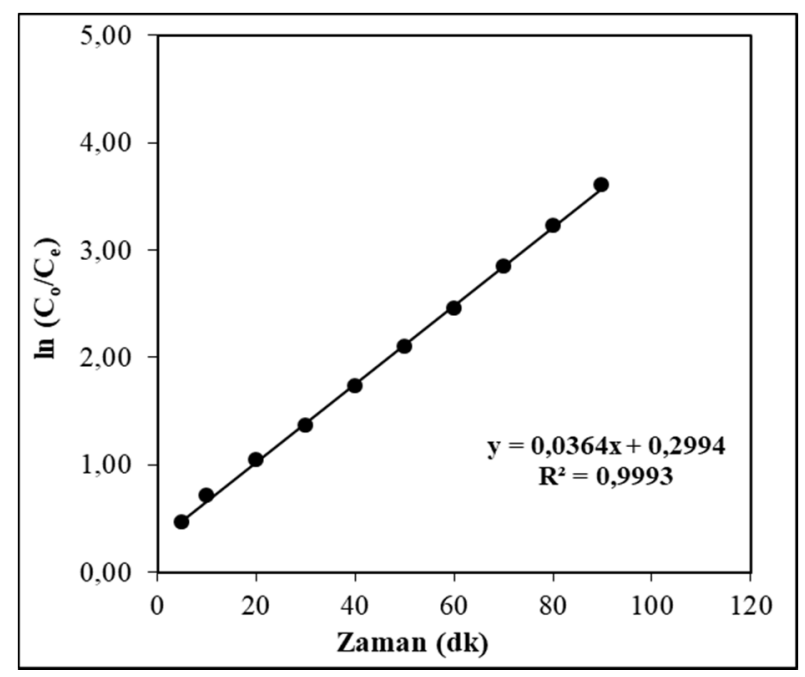

(b)

Şekil 4. (a) Donör, akseptör ve organik fazlardaki Molibden iyonları derişiminin zamanla değişim grafiğĭ, (b) Molibden için ekstraksiyon kinetiği grafiği 
ÇDSM sisteminde $\mathrm{Pb}^{2+}$ iyonlarının ekstraksiyonu için yapılan deneysel çalışmalarda taşıyıcı faz olarak kerozen içinde $1.50 \times 10^{-3} \mathrm{~mol} / \mathrm{L}$ D2EHPA ligantı en verimli sonuçları göstermiştir. Akseptör fazda $0.3 \mathrm{~mol} / \mathrm{L}$ 'lik $\mathrm{HNO}_{3}$ çözeltisi kullanılarak 298.15K'de \%98.77'lik bir ekstraksiyon verimi ile $\mathrm{Pb}^{2+}$ iyonları donör fazdan akseptör faza taşınmıştır. Aktivasyon enerjisi $\left(\mathrm{E}_{\mathrm{a}}\right)$ değerleri $7.41 \mathrm{kcal} / \mathrm{mol}$ olarak bulunmuş olup buradan $\mathrm{Pb}^{2+}$ iyonlarının taşınımının da difüzyon kontrollü olarak gerçekleştiği anlaşılmaktadır [14]. Fazlardaki kurşun metalinin zamanla değişim grafiği ve ekstraksiyon kinetiği grafikleri Şekil 5'te verilmiştir.

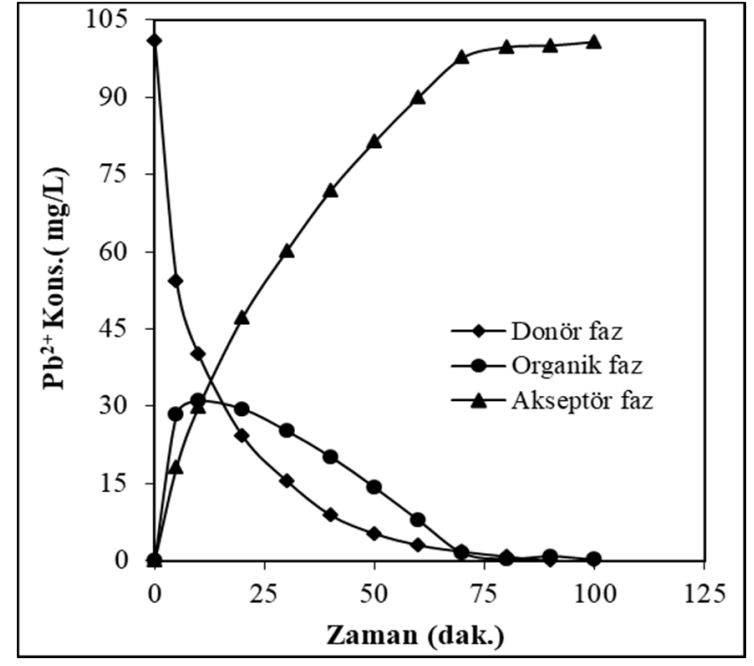

(a)

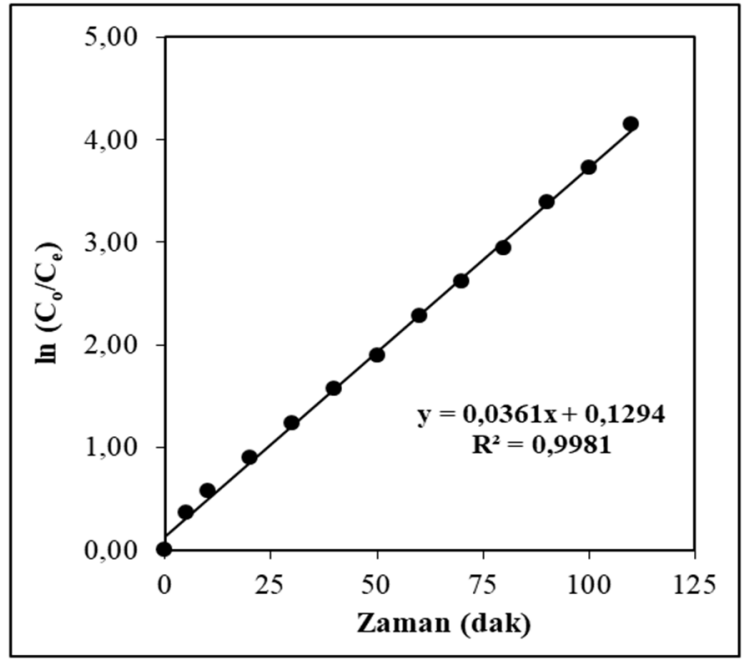

(b)

Şekil 5. (a) Donör, akseptör ve organik fazlardaki Kurşun iyonları derişiminin zamanla değişim grafiği, (b) Kurşun için ekstraksiyon kinetiği grafiği

Optimum koşullarda donör fazda $\mathrm{Pb}^{2+}$ iyonları yanında belli derişimlerde $\mathrm{Na}^{+}, \mathrm{K}^{+}, \mathrm{Ca}^{2+}$ ve $\mathrm{Ba}^{2+}$ iyonlarının bulunması halinde gerçekleştirilen yarışmalı ekstraksiyon deneylerinde; $\mathrm{Pb}^{2+}$ iyonlarının ekstraksiyon veriminin çok değişmediği gözlenmiştir. Bunun yanı sıra ekstraksiyon süresi uzamış, hız sabiti ve akış hızı değerleri düşmüştür. Yine optimum koşullarda donör fazda $\mathrm{Pb}^{2+}$ çözeltisi yanında $\mathrm{Mo}^{6+}, \mathrm{Fe}^{3+}, \mathrm{Cu}^{2+}$ ve $\mathrm{Zn}^{2+}$ iyonlarının bulunması halinde gerçekleştirilen yarışmalı ekstraksiyon deneylerinde de ortamda ağır metal iyonları varlığında seçimli ekstraksiyon çalışmalarında da $\mathrm{Pb}^{2+}$ iyonlarının ekstraksiyon veriminin çok değişmediği gözlenmiştir. Seçimli ekstraksiyon çalışmalarında ICP-OES ile yapılan ölçümler; akseptör fazda $\mathrm{Pb}^{2+}$ iyonlarıyla beraber donör fazdaki $\mathrm{Mo}^{6+}, \mathrm{Fe}^{3+}, \mathrm{Zn}^{2+}$ ve $\mathrm{Cu}^{2+}$ iyonlarının sırasıyla \%1.80, \%0.60, \%5.60 ve \%4.40 oranında akseptör faza taşındığını göstermiştir. İki değerlikli ağır metal iyonlarının diğer üç ve altı değerlikli metal iyonlarından daha fazla oranda akseptör faza taşındığı görülmektedir. Optimum şartlarda $\mathrm{Pb}$ (II) iyonlarının seçimli ekstraksiyon işlemlerinde ağır metal iyonlarının varlığında başarılı bir ekstraksiyonu gerçekleştirilmiş ve $\mathrm{Pb}^{2+}$ iyonlarının ekstraksiyonunda elde edilen geri alım verimlerinde azalmanın olmadığı tespit edilmiştir [13].

Bakır metali ile yapılan çalışmalarda; donör fazda pH değeri 9.00 olan bakır çözeltisinden organik fazda $5 \times 10^{-3} \mathrm{~mol} / \mathrm{L}$ 'lik TNOA kullanılmak suretiyle 1mol/L'lik $\mathrm{H}_{2} \mathrm{SO}_{4}$ çözeltisine ekstraksiyon çalışmaları 298.15K' de \%99.92 maksimum verimle gerçekleştirilmiştir. Aktivasyon enerjisi $\left(\mathrm{E}_{\mathrm{a}}\right)$ değeri $5.22 \mathrm{kcal} / \mathrm{mol}$ olarak hesaplanmış olup, $\mathrm{Cu}^{2+}$ iyonlarının taşınımının difüzyon kontrollü olarak gerçekleştiği anlaşılmaktadır. Fazlardaki $\mathrm{Cu}^{2+}$ iyonunun zamanla değişim grafiği ve ekstraksiyon kinetiği grafikleri Şekil 6' da verilmiştir [15]. 


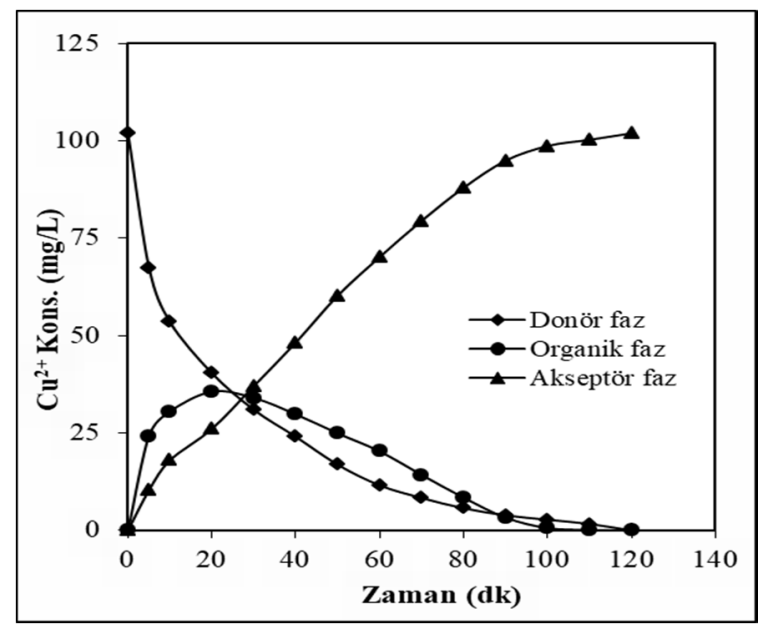

(a)

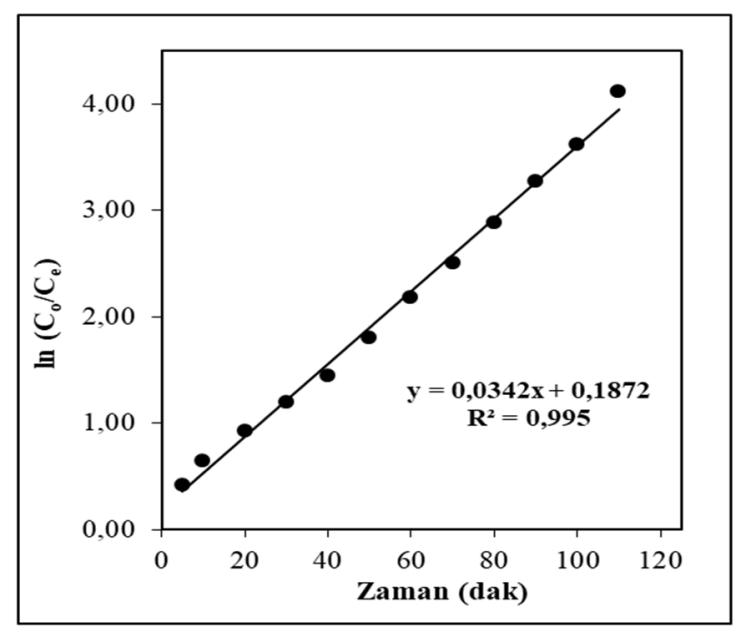

(b)

Şekil 6. (a) Donör, akseptör ve organik fazlardaki Bakır iyonları derişiminin zamanla değişim grafiğii, (b) Bakır için ekstraksiyon kinetiği grafiği

Donör fazda $\mathrm{Cu}^{2+}$ iyonları yanında $\mathrm{Na}^{+}, \mathrm{K}^{+}, \mathrm{Ca}^{2+}$ ve $\mathrm{Ba}^{2+}$ iyonlarının bulunması halinde gerçekleştirilen yarışmalı ekstraksiyon deneylerinde; $\mathrm{Cu}^{2+}$ iyonlarının transportunda ekstraksiyon veriminin çok değişmediğgi, ekstraksiyon süresinin uzadığı, hız sabiti ve akış hızının azaldığı gözlenmiştir. Seçimli ekstraksiyon çalışmalarında alev fotometresi ile yapılan ölçümler sonucunda akseptör fazda $\mathrm{Na}^{+}, \mathrm{K}^{+}, \mathrm{Ba}^{2+}$ iyonlarına rastlanmamış olup sadece; $\mathrm{Ca}^{2+}$ iyonu ise yaklaşık \%12.00 oranında akseptöre geçiş yapmıştır. Diğer ağır metallerin $\left(\mathrm{Fe}^{3+}, \mathrm{Zn}^{2+}, \mathrm{Mo}^{6+}\right)$ varlığında $\mathrm{Cu}^{2+}$ ekstraksiyonunu incelemek amaciyla optimum koşullarda gerçekleştirilen deneyler neticesinde $\mathrm{Cu}^{2+}$ iyonlarının ekstraksiyon verimi değerlerinin aynen kurşun ve molibden iyonlarında olduğu gibi çok değişmediği, ekstraksiyon süresinin uzadığı, hız sabit değerlerinin değiştiği ve akış hızının azaldığı belirlenmiştir. Seçimli ekstraksiyon çalışmalarında ICP-OES ile yapılan ölçümler sonucunda akseptör fazda $\mathrm{Cu}^{2+}$ iyonlarıyla beraber donör fazdaki $\mathrm{Mo}^{6+}, \mathrm{Fe}^{3+}, \mathrm{Zn}^{2+}$ iyonlarının sırasıyla \%2.20, \%0.80 ve \%3.60 oranında akseptör faza taşınmıştır [15].

Demir metalinin ÇDSM sistemi kullanılarak ekstraksiyonu çalışmalarında organik fazda $3.75 \times 10^{-}$ ${ }^{3} \mathrm{~mol} / \mathrm{L}$ TOPO ve akseptör fazda $2 \mathrm{~mol} / \mathrm{L} \mathrm{NaCl} 298.15 \mathrm{~K}$ sabit sıcaklıkta \%99 verimle taşınması sağlanmıştır. $\mathrm{Fe}^{3+}$ iyonlarının ekstraksiyon mekanizmasına ait aktivasyon enerjisi $25.79 \mathrm{kcal} / \mathrm{mol}$ olarak hesaplanmış olup; bu değer çok damlacıklı membran sistemi ile $\mathrm{Fe}^{3+}$ iyonlarının ekstraksiyonunun kimyasal kontrollü olduğunu göstermiştir [16].F azlardaki $\mathrm{Fe}^{3+}$ iyonları derişiminin zamanla değişim grafiği ve ekstraksiyon kinetiği grafikleri Şekil 7'te verilmiştir.

Donör fazda $\mathrm{Fe}^{3+}$ iyonları yanında $\mathrm{K}^{+}, \mathrm{Ca}^{2+}$ ve $\mathrm{Ba}^{2+}$ iyonlarının bulunması halinde gerçekleştirilen yarışmalı ekstraksiyon deneylerinde; $\mathrm{Fe}^{3+}$ iyonlarının transportunda ekstraksiyon verimin çok değişmediği, ekstraksiyon süresinin uzadığı, hız sabiti ve akış hızının azaldığı gözlenmiştir. Seçimli ekstraksiyon çalışmalarında alev fotometresi ile yapılan ölçümler sonucunda akseptör fazda $\mathrm{Na}^{+}$iyonlarına rastlanmamış olup; $\mathrm{Ca}^{2+}$ ve $\mathrm{Ba}^{2+}$ iyonları ise sırasıyla yaklaşık $\% 13.10$ ve $\% 5.00$ oranında akseptöre geçiş yapmıştır. Diğer ağır metallerin $\left(\mathrm{Cu}^{2+}, \mathrm{Zn}^{2+}, \mathrm{Mo}^{6+}, \mathrm{Pb}^{2+}\right.$ ve $\left.\mathrm{Co}^{2+}\right)$ varlığında $\mathrm{Fe}^{3+}$ ile yarışmalı ekstraksiyonu incelendiğinde $\mathrm{Fe}^{3+}$ iyonlarının ekstraksiyon verimlerinin çok değişmediği, ekstraksiyon süresinin uzadığı, hız sabit değerlerinin değiştiği ve akış hızının azaldığı belirlenmiştir. Bu deneyler sonucunda akseptör fazda $\mathrm{Fe}^{3+}$ iyonlarıyla beraber donör fazdaki $\mathrm{Cu}^{2+}, \quad \mathrm{Mo}^{6+}, \quad \mathrm{Pb}^{2+}, \quad \mathrm{Zn}^{2+}$ ve $\mathrm{Co}^{2+}$ iyonlarının akseptör faza geçişleri sırasıyla $\% 12.04, \% 1.20, \% 14.62, \% 16.28$ ve $\% 10.32$ oranlarında gerçekleşmiştir [13]. 


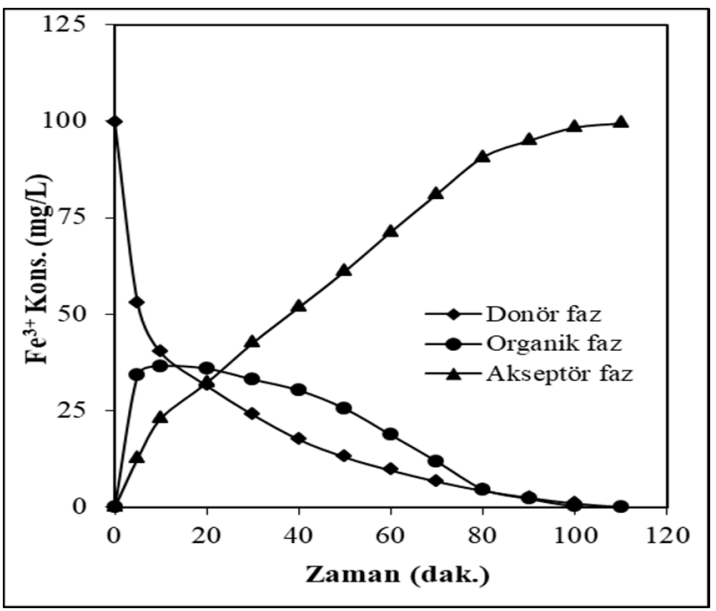

(a)

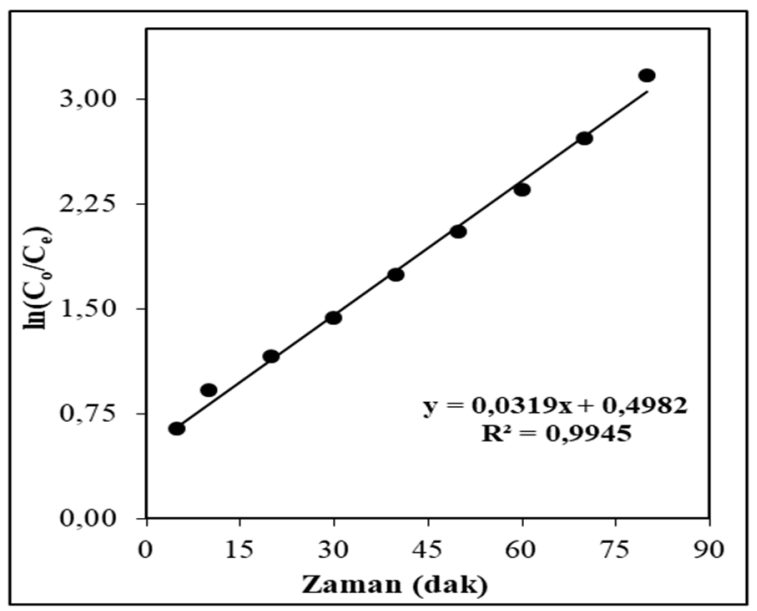

(b)

Şekil 7. (a) Donör, akseptör ve organik fazlardaki Demir iyonları derişiminin zamanla değişim grafiği, (b) Demir için ekstraksiyon kinetiği grafiği

Optimum taşınım koşulları belirlendikten sonra ve her bir metal iyonu taşınımına ait kinetik veriler hesaplanmıştır. Elde edilen sonuçlar toplu halde Tablo 1'de verilmiştir.

Tablo 1. Çok Damlacıklı Sıvı Membran Sistemi ile ekstraksiyonu incelenen tüm iyonlar için optimum koşullar ve kinetik parametreler

\begin{tabular}{|c|c|c|c|c|c|c|}
\hline & $\mathbf{Z n}^{2+}$ & $\mathbf{C d}^{2+}$ & $\mathrm{Mo}^{6+}$ & $\mathbf{P b}^{2+}$ & $\mathrm{Cu}^{2+}$ & $\mathrm{Fe}^{3+}$ \\
\hline Donör Faz Derişimi (mg/L) ve pH'sı & $\begin{array}{c}120 \\
\mathrm{pH}: 5\end{array}$ & $\begin{array}{c}100 \\
\mathrm{pH}: 2.5\end{array}$ & $\begin{array}{c}100 \\
\mathrm{pH}: 2\end{array}$ & $\begin{array}{c}100 \\
\mathrm{pH}: 7\end{array}$ & $\begin{array}{c}100 \\
\mathrm{pH}: 9\end{array}$ & $\begin{array}{c}100 \\
\mathrm{pH}: 1\end{array}$ \\
\hline Taşıyıcı Ligand Türü ve Derişimi, (mg/L) & $\begin{array}{l}\text { D2EHPA } \\
\left(8.0 \times 10^{-3}\right)\end{array}$ & $\begin{array}{c}\text { TNOA } \\
\left(7.0 \times 10^{-3}\right)\end{array}$ & $\begin{array}{c}\text { TNOA } \\
\left(5.0 \times 10^{-3}\right)\end{array}$ & $\begin{array}{c}\text { D2EHPA } \\
\left(1.50 \times 10^{-2}\right)\end{array}$ & $\begin{array}{c}\text { TNOA } \\
\left(5.0 \times 10^{-3}\right)\end{array}$ & $\begin{array}{c}\text { TOPO } \\
\left(1.5 \times 10^{-2}\right)\end{array}$ \\
\hline Sicaklık, $(K)$ & 308.15 & 298.15 & 298.15 & 298.15 & 298.15 & 298.15 \\
\hline Transfer hızı, (mL/dak) & 62 & 125 & 50 & 50 & 50 & 140 \\
\hline$k_{1} 10^{2}\left(\mathrm{dak}^{-1}\right)$ & 8.84 & 5.62 & 3.64 & 3.62 & 3.42 & 3.19 \\
\hline$k_{2} 10^{2}\left(\mathrm{dak}^{-1}\right)$ & 16.33 & 74.25 & 6.19 & 5.22 & 3.66 & 12.51 \\
\hline$J_{d}^{m a k} 10^{2}$ (dak) & -4.284 & -4.55 & -1.71 & -1.58 & -1.30 & -19.98 \\
\hline$J_{a}^{m a k} 10^{2}$ (dak) & 4.284 & 4.55 & 1.71 & 1.58 & 1.30 & 19.98 \\
\hline$E_{a}(\mathrm{kcal} / \mathrm{mol})$ & 5.30 & 17.07 & 6.09 & 7.41 & 5.22 & 25.79 \\
\hline
\end{tabular}

Literatürde mevcut değişik sıvı membran sistemleri ile yapılan bazı ekstraksiyon çalışmaları Tablo 2'de verilmiştir. Sıvı membranlar ile metal iyonu ekstraksiyonuna dair yapılmış çok fazla sayıda çalışma mevcuttur. Tablo 2'de yer alan çalışmalar nispeten yüksek verimle sonuçlanmış çalışmalardan bazılarıdır. Tablo 2, Tablo 1 ile kıyaslanacak olursa; yeni tasarlanmış ÇDSM sistemi ile elde edilen sonuçların literatürde mevcut klasik çalışmalar ile kıyaslanabilir ölçüde iyi olduğu açıkça görülmektedir. 
Tablo 2. ÇDSM sisteminde incelenmiş tüm iyonlar için literatürde yer alan değişik sıvı membran sistemleri ile yapılmış ekstraksiyon çalışmaları

\begin{tabular}{|c|c|c|c|c|c|c|}
\hline $\begin{array}{l}\text { Ekstrakte Edilen } \\
\text { Metal }\end{array}$ & $\mathbf{Z n}^{2+}$ & $\mathrm{Cd}^{2+}$ & $\mathrm{Mo}^{6+}$ & $\mathbf{P b}^{2+}$ & $\mathrm{Cu}^{2+}$ & $\mathrm{Fe}^{3+}$ \\
\hline Membran Sistemi & BLM & SLM & ELM & HFSLM & BLM & $\overline{\text { SLM }}$ \\
\hline Taşıyıcı Ligand & D2EHPA & TBP & $\begin{array}{l}\text { Aliquat336-Cl } \\
\text { Aliquat336-OH }\end{array}$ & D2EHPA & $\begin{array}{c}\text { LIX984N } \\
\text { Cyanex272 } \\
\text { D2EHPA }\end{array}$ & Aliquot \\
\hline Organik Çözücü & Kerosen & Siklohegzan & Dodekan & Toluen & Kerosen & Ksilen \\
\hline Akseptör Faz & $\mathrm{HCl}$ & EDTA & $\mathrm{NaOH}$ & $\mathrm{HCl}$ & $\mathrm{H}_{2} \mathrm{SO}_{4}$ & $6 \mathrm{M} \mathrm{HCl}$ \\
\hline Transfer Yüzdesi, (\%) & $\% 98.8$ & $\% 85.4$ & $\begin{array}{l}\% 85 \\
\% 75\end{array}$ & $\% 97$ & $\begin{array}{l}\% 80 \\
\% 75 \\
\% 70\end{array}$ & $\% 99$ \\
\hline Referans & [17] & {$[18]$} & [19] & {$[20]$} & [21] & {$[22]$} \\
\hline
\end{tabular}

\section{SONUÇLAR}

ÇDSM sisteminde yapılan onlarca çalışma ve gerçekleştirilen yüzlerce deney neticesinde $\mathrm{Zn}^{2+}, \mathrm{Cd}^{2+}$, $\mathrm{Mo}^{6+}, \mathrm{Pb}^{2+}, \mathrm{Cu}^{2+}, \mathrm{Fe}^{3+}$ iyonlarının ÇDSM sistemi için belirlenen optimum taşınım koşulları altında \%95'in üzerinde ekstraksiyon verimi ile taşınımının mümkün olduğu görülmüştür. Her bir metal iyonu için uygun olan organik ve alıcı fazlar belirlenmiştir. Ayrıca bu metaller için ÇDSM sisteminde ekstraksiyon kinetiğgi de açıklanmış olup oldukça kapsamlı bir çalışma gerçekleştirilmiştir.

Elde edilen verilerin değerlendirilmesi sonucunda, ÇDSM sisteminin diğer sıvı membran sistemlerine göre kolay uygulanabilirliği, yüksek membran kapasitesi, az miktarda organik ligant kullanılması, metal iyonlarının taşınım süresinin kısalığı ve endüstriyel atık metal iyonlarının seçimli eksraksiyonunda kullanılabilirliği gibi bazı önemli avantajlarının olduğu görülmüştür. MDLM sistemi diğer membran sistemleri ile kıyaslandığında en çok BLM (Hacimli sıvı membranlar) sistemi ile benzerlik göstermektedir. Mevcut membran sistemlerinden en belirgin fark1; ÇDSM sisteminin hareketli olmasından dolayı ekstraksiyonda süreklilik sağlaması ve donör faz ile akseptör faz reaktörlerinin tabanındaki poröz camlarla elde edilen damlacıklar sayesinde yüzey alanı genişletilerek organik ligandla sulu çözeltilerdeki metal iyonlarının etkileşiminin artması neticesinde ekstraksiyonun veriminin artması ve süresinin kısaltılmasıdır. Bu da ekonomik açıdan daha az organik ligandla daha yüksek ekstraksiyon verimi elde edilmesini sağlamaktadır.

Sonuç olarak; taşıyıcı ligandlar ve sıvı membran sisteminin deneysel düzeneği kullanılarak verimli sonuçlar elde edilebilir. ÇDSM sıvı membran sistemi, uygun donör, ekstrakt, alıcı çözelti seçilmesi ve çalışma koşulları araştırılması suretiyle; ağır metal endüstrilerinin neden olduğu ağır metal iyonlarını gidermek amacıyla kullanılabilir. Bu sistem ile ağır metal içeren gerçek maden atık sularında donör ve akseptör faz reaktör boyutları arttırılarak seçimli olarak metallerin saflaştırılması ve zenginleştirilmesi gerçekleştirilebilir. Organik faz gerekli rejenerasyon işlemlerinden geçirildikten sonra tekrar ekstraktör olarak kullanılabilir. Bu çalışmanın ekonomik, hafif, taşınabilir, operasyonel olarak esnek olan sistem aynı şekilde donör ve alıcı faz reaktörlerinin genişlemesi ile atık su arıtma tesislerine entegre edilebileceği öngörülebilir.

\section{TEŞEKKÜR}

Bu araştırma çalışması finansal olarak Pamukkale Üniversitesi (Proje No: BAP2011FBE072, BAP2012FBE077) tarafından Bilimsel Araştırma Projesi olarak desteklenmiştir. 


\section{KAYNAKLAR}

[1] Järup, L. (2003). Hazards of heavy metal contamination. British Medical Bulletin, 68(1), 167-182.

[2] Isaac, R. A., Gil, L., Cooperman, A.N., Hulme, K., Eddy, B., Ruiz, M., Jacobson, K., Larson, C., Pancorbo, O.C. (1997). Corrosion in Drinking Water Distribution Systems: A Major Contributor of Copper and Lead to Wastewaters and Effluents. Environmental Science and Technology, 31, 3198-3203.

[3] Xiong, L., Chen, C., Chen, Q., Ni, J. (2011). Adsorption of $\mathrm{Pb}(\mathrm{II})$ and $\mathrm{Cd}(\mathrm{II})$ from aqueous solutions using titanate nanotubes prepared via hydrothermal method. Journal of Hazardous Materials 189, 741-748

[4] Ahluwalia, S. S., Goyal, D., (2005). Removal of heavy metals from waste tea leaves from aqueous solution. Engineering in Life Sciences 5, 158-162.

[5] Büyüktuncel, E. (2012). Gelişmiş Ekstraksiyon Teknikleri, Hacettepe Üniversitesi Eczacılık Fakültesi Dergisi 32(2), 209-242.

[6] Gürel L., Büyükgüngör H., (2006). Liquid membranes in advanced treatment, Mühendislik ve Fen Bilimleri Dergisi, 2, (30-44).

[7] Şenvar, C. (1986). Kimyasal Kinetik ve Makromoleküller,Fizikokimya Cilt IV, Marmara Üniversitesi Yayınları, İstanbul.

[8] Erdoğdu, F., Şahmurat, F. (2007). Mathematical fundamentals to determine the kinetic constants of firstorder consecutive reactions, Journal of Food Process Engineering, 30, 407-420.

[9] Yilmaz, A., Kaya, A., Alpoguz, H.K. , Ersoz, M., Yilmaz, M. (2008). Kinetic analysis of chromium(VI) ions transport through a bulk liquid membrane containing p-tert-butylcalix[4]arene dioxaoctylamide derivative, Seperation and Purification Technology, 59(1), 1-8.

[10] Erden, K. E., Donat, R. (2018). Transportation and kinetic analysis of Zn(II) ions via MDLM system containing D2EHPA as carrier, Membrane Water Treatment, 19(1), 23-31.

[11] Donat, R., Eyice, M.İ. (2018). Extraction of $\mathrm{Cd}^{2+}$ ions from MDLM System with TNOA carrier, Marmara Fen Bilimleri Dergisi, 4, 467-477.

[12] Donat, R., Durmaz, Ö., Cetisli, H. (2015). Transportation and kinetic analysis of Mo(VI) ions through a MDLM system containing TNOA as carrier, Journal of Hazardous Materials, 294, 17-26.

[13] Durmaz, Ö. (2016). Sıvı membran tekniği ile bazı ağır metal iyonlarının ekstraksiyonunun incelenmesi, Doktora Tezi, Pamukkale Üniversitesi Fen Bilimleri Enstitüsü, Denizli.

[14] Durmaz, Ö., Donat, R., Cetisli, H. (2016). Transportation of Pb(II) ions with D2EHPA as Carrier by MDLM System, International Journal of Innovative Research in Science, Engineering and Technology, 5(12), 47-56.

[15] Donat, R., Durmaz, Ö., Cetisli H. (2017). The kinetic analysis of optimization and selective transportation of $\mathrm{Cu}(\mathrm{II})$ ions with TNOA as carrier by MDLM system, Chinese Journal of Chemical Engineering, 25, $415-425$.

[16] Donat, R., Durmaz, Ö. (2019). Extraction of Fe(III) Ions through MDLM System Containing TOPO as Carrier, Ĭgdır Üniversitesi Fen Bilimleri Enstitüsü Dergisi, 9(2), 944-955.

[17] Singh, R., Mehta, R., Kumar, V. (2011) Simultaneous removal of copper, nickel and zinc metal ions using bulk liquid membrane system, Desalination, 272 (1-3), 170-173. 
[18] Nowier, H.G., El-Said, N., Aly, H.F. (2000). Carrier-mediated transport of toxic elements through liquid membranes: Transport of $\mathrm{Cd}(\mathrm{II})$ from high salinity chloride medium through supported liquid membrane containing TBP/cyclohexane, Journal of Membrane Science, 177(1-2), 41-47.

[19] Kulkarni, P.S., Mahajani, V.V. (2002). Application of liquid emulsion membrane (LEM) process for enrichment of molybdenum from aqueous solutions, Journal of Membrane Science 201, 123-135

[20] Suren S., Pachaoren, U., Kheawhom, S. (2014). Simultaneous extraction and stripping of lead ions via a hollow fibersupported liquid membrane: Experiment and modeling. Journal of Industrial and Engineering Chemistry, (20), 2584-2593.

[21] Leon, G., Guzman, M.A. (2008). Facilitated transport of copper through bulk liquid membranes containing different carriers: compared kinetic study, Desalination, 223, 330-336.

[22] Buonomenna, M.G., Molinari, R., Drioli, E. (2002). Selective mass transfer of iron(II1) in supported liquid membrane using highly acidic extractants, 3-phenyl-4-acyl-5-isoxazolones, Desalination, 148, 257-262. 